\title{
Helical Antenna sensor for Different Liquid Type Identification
}

\author{
Waleed Majdi Issa Ikhmis, Saidatul Norlyana Azemi, Azremi Abdullah Al-Hadi, Ping Jack Soh, Mohd Faizal Jamlos
}

Advanced Communication Engineering Centre (ACE) CoE, School of Computer and Communication Engineering, Universiti Malaysia Perlis (UniMAP), Pauh Putra, Arau 02600, Malaysia.

\begin{abstract}
There are variety of lliquid sensor measurement systems that available in the market nowadays. It is used to measure various parameter for wide range application or to address a specific application. However, most of the existing monitoring system still involved bulky equipment and required a quite amount or liquid to be tested. The results obtained time consuming and take a long time to obtain the desired results. To solve the problems, we develop and design a small sensor using antenna that is small, robust as well as reliable and efficient to work as a sensor for liquid sensor detection. It is efficient and reliable to obtain in-situ result. The helical antenna is design using CST Software and the fabricated antenna is measured. The helical antenna works on $2 \mathrm{GHz}$ frequency is tested with three different type of liquids and it is shows different liquid has their own frequency shift.
\end{abstract}

\section{Introduction}

Sensor is a device that responds and detects to some type of input from the physical environment. The specific input could be heat, light, motion, moisture and pressure. The output is generally a signal that is converted to human-readable display at the sensor location or transmitted electronically over a network for further processing or reading [1-5]. Real time oil quality monitoring techniques help to protect important industry assets, minimize downtime and reduce maintenance costs. The measurement of a lubricant's complex permittivity is an effective indicator of the liquid degradation process and it can be useful in condition based maintenance (CBM) to select the most adequate liquid replacement maintenance schedules [4]. Following shows an example of the liquid sensor that available in the market.

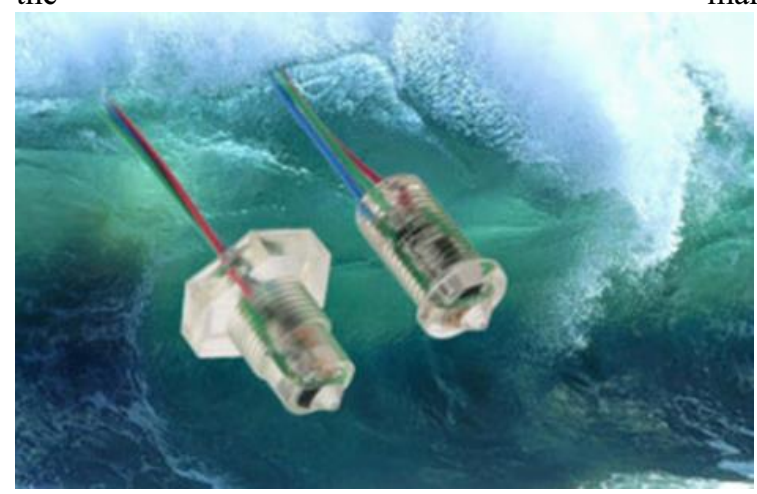

Fig. 1. Example of liquid sensor [1].

The family of liquid measurement systems is classified into different categories such as:

- Liquids or Solids Level Measurement

- Point or Continuous Level Measurement

- Electromagnetic or Electromechanical Level Measurement

\section{- Contacting or Non-Contacting Level Measurement}

Analytical, computational (finite element analysis) and experimental tests conducted has demonstrated that antennas can be used as a sensor. In addition, their straightforward integration with electronics has opened new fields of application such as smart sensing systems. Here, a helical antenna will be used as a sensor for this project because it is cheap, robust and chemical free. The example of helical antenna sensor shown in figure 2 .

In this paper, a helical antenna is proposed to be used as sensor to detect a different type of liquid. It is cost effective wireless liquid type monitoring utilizing and helical antenna sensor. Different core materials with different effective permittivity will affect the radiation properties of the antenna. When the antenna core are loaded with liquids, the resonant frequency will sensitively change the antenna resonant frequency and return loss according to the permittivity value of the drug. This in turn increases the voltage standing wave ratio (VSWR) at the measuring frequency. The increase in VSWR affects the reflection coefficient as shown by (1), which in turn changes the return loss at the measuring frequency, as shown by (2) [6].

$$
\begin{aligned}
& \text { Reflection Coefficient }|\tau|=\frac{|V S W R-1|}{|V S W R+1|} \\
& \text { Return Loss }=-20 \log |\tau|
\end{aligned}
$$

\section{Helical antenna sensor developments}

Scope of this research was to develop a new method in antenna design in order to obtain the best performing of antenna with parametric studies. As for antenna specification, there are a few essential parameters in designing the antenna. As shown in figure 2 is the simple helical antenna design.

\footnotetext{
*Corresponding author: ikh.waleed@gmail.com
} 
Following are the formulas of helical antenna [6]:

$$
\begin{aligned}
& \text { Characteristic Impedance }(Z)=\frac{150}{\sqrt{C / \lambda}} \\
& \text { Antenna Diameter, }(D)=\frac{\lambda}{\pi} \quad \\
& \text { Spacing between coils }(S)=\frac{C}{4} \\
& \text { Half power beamwidth }(H P B W)=\frac{52}{\left(\frac{c}{\lambda}\right)\left(\sqrt{\frac{N S}{\lambda}}\right)}
\end{aligned}
$$

$$
\begin{gathered}
\text { Beamwidth for the 1st null: } \frac{115}{\left(\frac{c}{\lambda}\right)\left(\sqrt{\frac{N S}{\lambda}}\right)} \\
\text { Effective Aperture }(A e)=\frac{D \lambda^{2}}{4 \pi}
\end{gathered}
$$

Where:

$D$ : Diameter of a turn on the helical antenna.

$N$ : Number of turns on the helical antenna.

$S$ : Vertical separation between turns for helical antenna.

$C$ : Circumference of a turn on the helical antenna $\pi \mathrm{D}$.

Table 1. Antenna Parameter.

\begin{tabular}{|l|c|}
\hline Parameter & Value \\
\hline$\lambda$ (wavelength) & 0.150 \\
\hline$f$ (frequency) & $2000 \mathrm{MHz}$ \\
\hline$N$ (Number of Turns) & 3 \\
\hline$S$ (Spacing between coils) & $0.25 \mathrm{~cm}$ \\
\hline$G$ (Antenna Gain) & $6 \mathrm{~dB}$ \\
\hline $\begin{array}{l}Z \text { (Characteristic } \\
\text { Impedance) }\end{array}$ & $150 \Omega$ \\
\hline$D$ (Diameter) & $4.77 \mathrm{~cm}$ \\
\hline$S$ (Spacing between coils) & $3.75 \mathrm{~cm}$ \\
\hline L (Length of wire) & $8 \mathrm{~cm}$ \\
\hline HPBW (Half Power BW) & $60.0^{\circ}$ \\
\hline$B W F N$ (BW first nulls) & $133^{\circ}$ \\
\hline$A e$ (Effective Apertures) & $0.0161 \mathrm{~m}$ \\
\hline
\end{tabular}

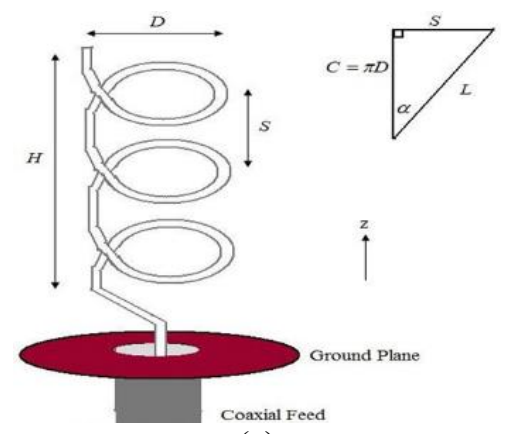

(a)

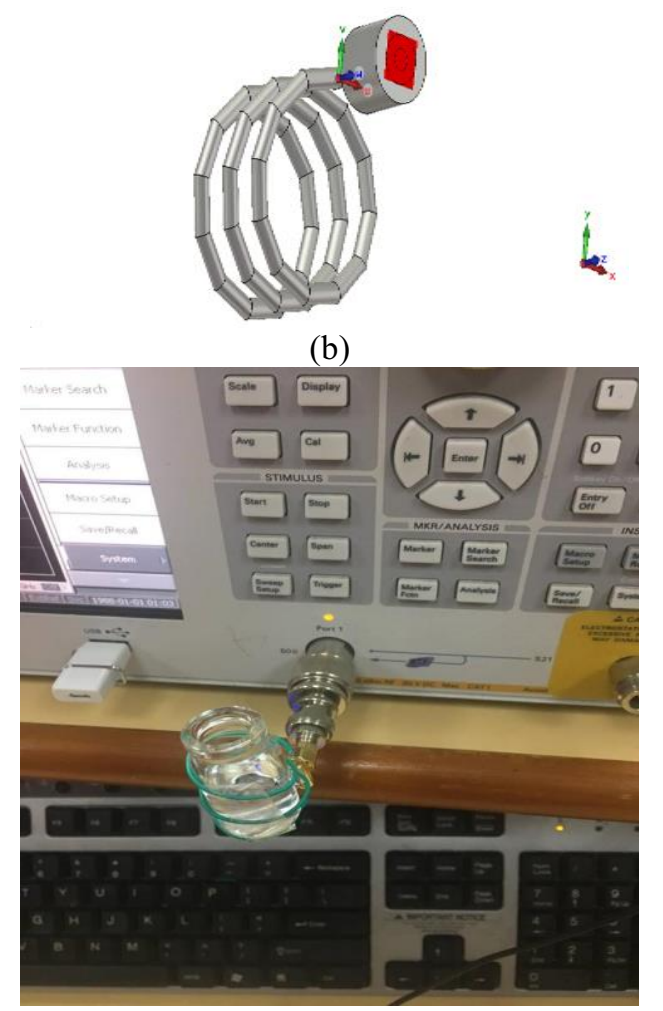

Fig. 2. Simple Helical Antenna. (a) Helical antenna (b) helical antenna design using CST (c) Helical antenna under test with an empty bottle.

\section{Result and discussion}

\subsection{Helical antenna sensor results}

The simulation and measured result for $S_{11}$ are shown in figure 3 where both result simulation and measurement are approximately the same. The simulation and measured results are in good agreement with each other which is shows that the antenna operating at $2 \mathrm{GHz}$. From the experiment, it is found out that the antenna copper wire angle of the design hardware will affect the result. These may happen because of manual fabrication and designing hardware where the angle is very difficult to make it $90^{\circ}$ which is like a sharp angle as same in simulation design. The length of copper wire of antenna played a significant role because of the curved angle not sharply $90^{\circ}$ and possibility length of copper wire is more than the simulation design. From the analysis, slightly different of the length and the curved angle antenna will affect the actual result. Nevertheless, the percentage different is only $1 \%$. Return loss value of the measured result shows that it is in good value for the radiation signal where the insertion loss value is less than $-10 \mathrm{~dB}$.

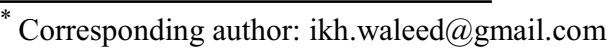




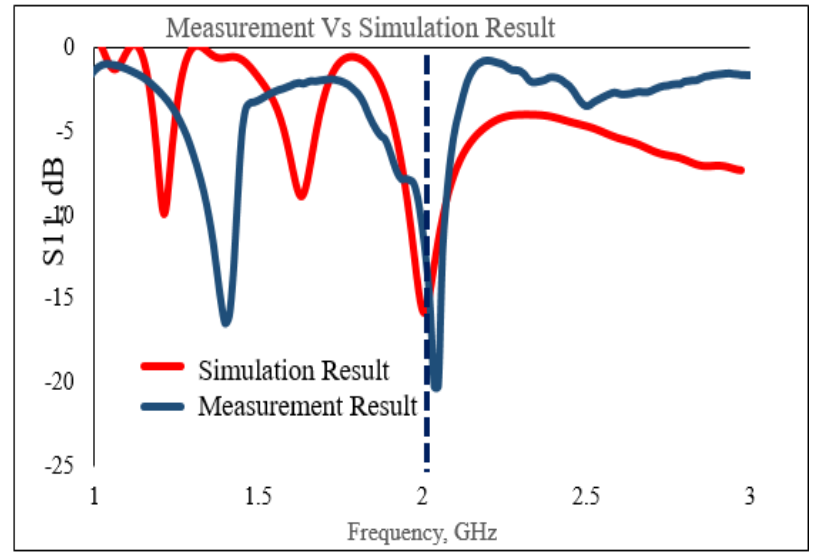

Fig. 3. $S_{11}$ Measurement Vs Simulation Result

\subsection{VSWR measurement Vs simulation result.}

Shown in figure 4 is VSWR measurement versus simulation result. It is shows that, both of the results are approximately the same. VSWR is the ratio of the maximum voltage to the minimum voltage in standing wave pattern along the length of a transmission line structure. It is varies from $2 \mathrm{GHz}$ to (plus) infinity and is always positive. From the result, all the value is positive at the targeted frequency and it is approaching to $2 \mathrm{GHz}$.

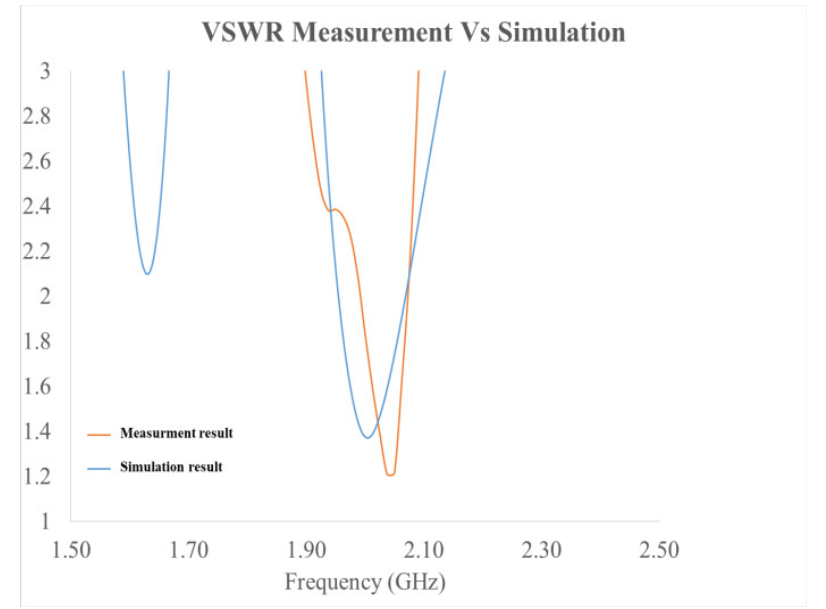

Fig. 4. VSWR Measurement Vs Simulation Result.

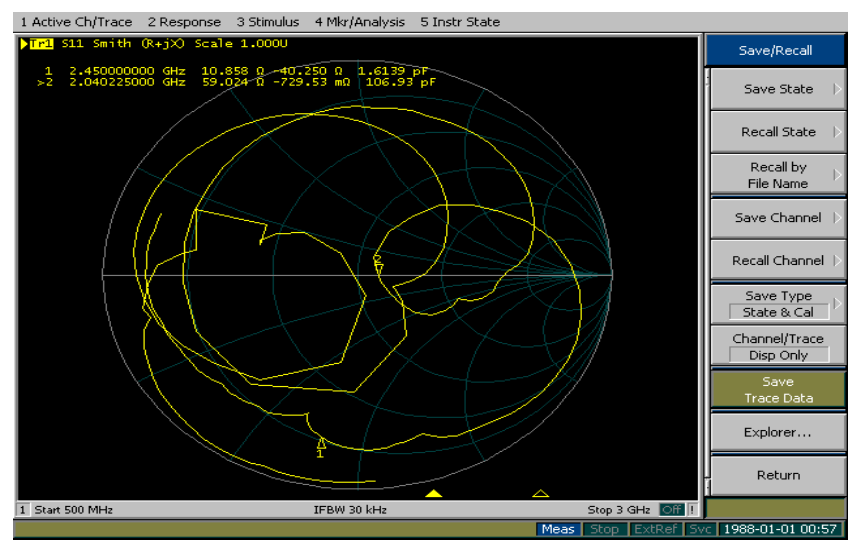

Fig.5. Smith chart at $2 \mathrm{GHs}$ frequency and $2.45 \mathrm{GHz}$.

\footnotetext{
*Corresponding author: ikh.waleed@gmail.com
}

As shows in figure 5 is the result of impedance using network analyser. As can be seen when the frequency is at $2.45 \mathrm{GHz}$ the value is $10.85 \Omega$, but when the frequency $2 \mathrm{GHZ}$ the value is 59 $\Omega$ which is accurate because near to the $50 \Omega$.

\subsection{Gain}

Antenna gain is the main performance which is combined the antennas directivity and electrical efficiency. It is shows the amount of energy radiated in a particular direction compared to the amount of energy directed in the same direction of an isotropic antenna [6]. For this helical antenna gain value is $6.46 \mathrm{~dB}$, and pointing toward $\mathrm{z}$ plane, as shown in figure 6 .
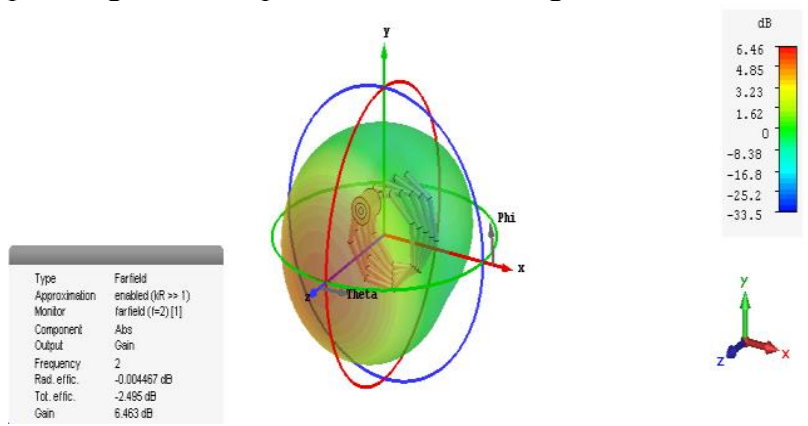

Fig. 6. Helical antenna radiation pattern, pointing toward $\mathrm{z}$ plane, the gain is $6.46 \mathrm{~dB}$.

\subsection{Summary of the measurements}

The graph bellow as shows in figure 7 shows the measurements results for the chosen materials. The experiment results are compared with the approximation simulation performance whenever to verify that the design perform as presented. Once filling the bottle with liquid, the frequency will decreases depending on the type of the liquid.

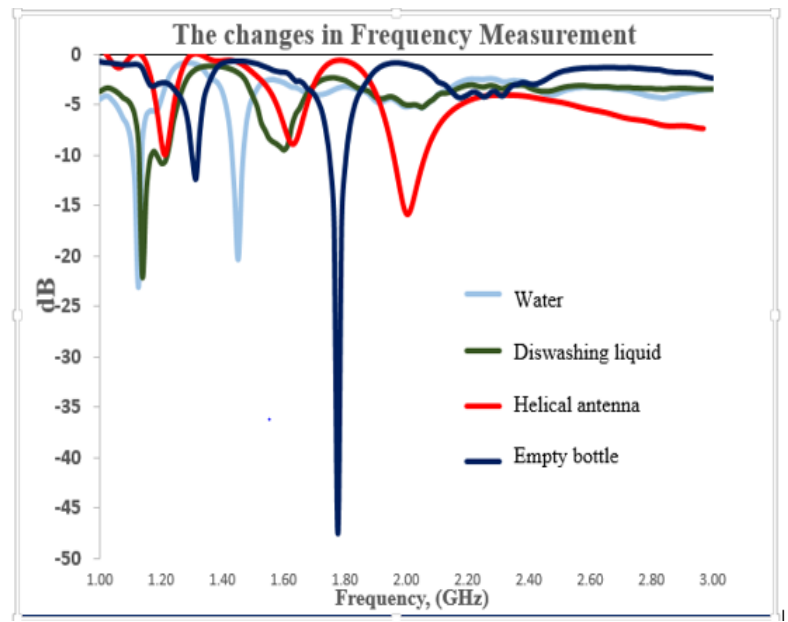

Fig. 7. The graph shows the measurement result. 
Table 2. Summary of measurements results based on changes with resonant frequency.

\begin{tabular}{|l|l|l|}
\hline Material & $\begin{array}{l}\text { Frequency } \\
(\mathrm{GHz})\end{array}$ & Bandwidth dB \\
\hline Helical antenna & $2 \mathrm{GHz}$ & $-15 \mathrm{~dB}$ \\
\hline $\begin{array}{l}\text { Helical antenna with } \\
\text { empty bottle }\end{array}$ & $1.8 \mathrm{GHz}$ & $-47 \mathrm{~dB}$ \\
\hline $\begin{array}{l}\text { Helical antenna with } \\
\text { dishwashing liquid }\end{array}$ & $1.2 \mathrm{GHz}$ & $-22 \mathrm{~dB}$ \\
\hline $\begin{array}{l}\text { Helical antenna with } \\
\text { water }\end{array}$ & $1.18 \mathrm{GHz}$ & $-23 \mathrm{~dB}$ \\
\hline
\end{tabular}

\section{Conclusion}

Based on the results that had been discussed in the paper, it had been proved that the objectives of this project have been achieved successfully and can be fabricated to measure the frequency for the liquids. Firstly, the design uses a small sensor using helical antenna that is small, suitable and robust. Secondly, the fabricated sensor antenna for liquid sensor detection that is efficient and reliable. Besides that, the helical antenna was evaluated and verified in order to overcome the disadvantages of current antenna which is bulky in size compared to their wavelength. This antenna proved that the size in term of wavelength is small enough compared than previous antenna design.

\section{References}

1. D. Fine et al., A robust nano uidic membrane with tunable zero-order release for implantable dose speci_c drug delivery,Lab Chip, vol. 10, no. 22, pp. 3074-3083, Nov. 2010.

2. A. Oseev, R. Lucklum, M. Zubtsov, M.P. Schmidt, and S. Hirsch, SAW based phononic crystal liquid sensor-Periodic microfluidic channels approach. Ultrasonics Symposium (IUS), 2016 IEEE International, pp. 1-4. 2016

3. E. Bou-Maroun, J. Rossignol, B. De Fonseca, C. Lafarge, R.D. Gougeon, D. Stuerga, D. and P. Cayot, Feasibility of a microwave liquid sensor based on molecularly imprinted sol-gel polymer for the detection of iprodione fungicide. Sensors and Actuators B: Chemical, 244, pp.24-30, 2017.

4. Ma, T.X., Wang, Y.S., Zhang, C. and Su, X.X., 2016. Theoretical research on a twodimensional phoxonic crystal liquid sensor by utilizing surface optical and acoustic waves. Sensors and Actuators A: Physical, 242, pp.123-131, 2016.

5. M.A.M. Johari, A.M. Azize, R.M. Said, N.A. Ngatiman, and N. Zaine, Corn Oil Concentrations Detection for Food Industry Research Development by Using Application of Fiber Optic Liquid Sensor Concept. In MATEC

\footnotetext{
* Corresponding author: ikh.waleed@gmail.com
}

Web of Conferences (Vol. 97, p. 01108). EDP Sciences, 2017.

6. C. A. Balanis, Antenna Theory: Analysis and Design, 3rd ed. New York,NY, USA: Wiley, 2005. 